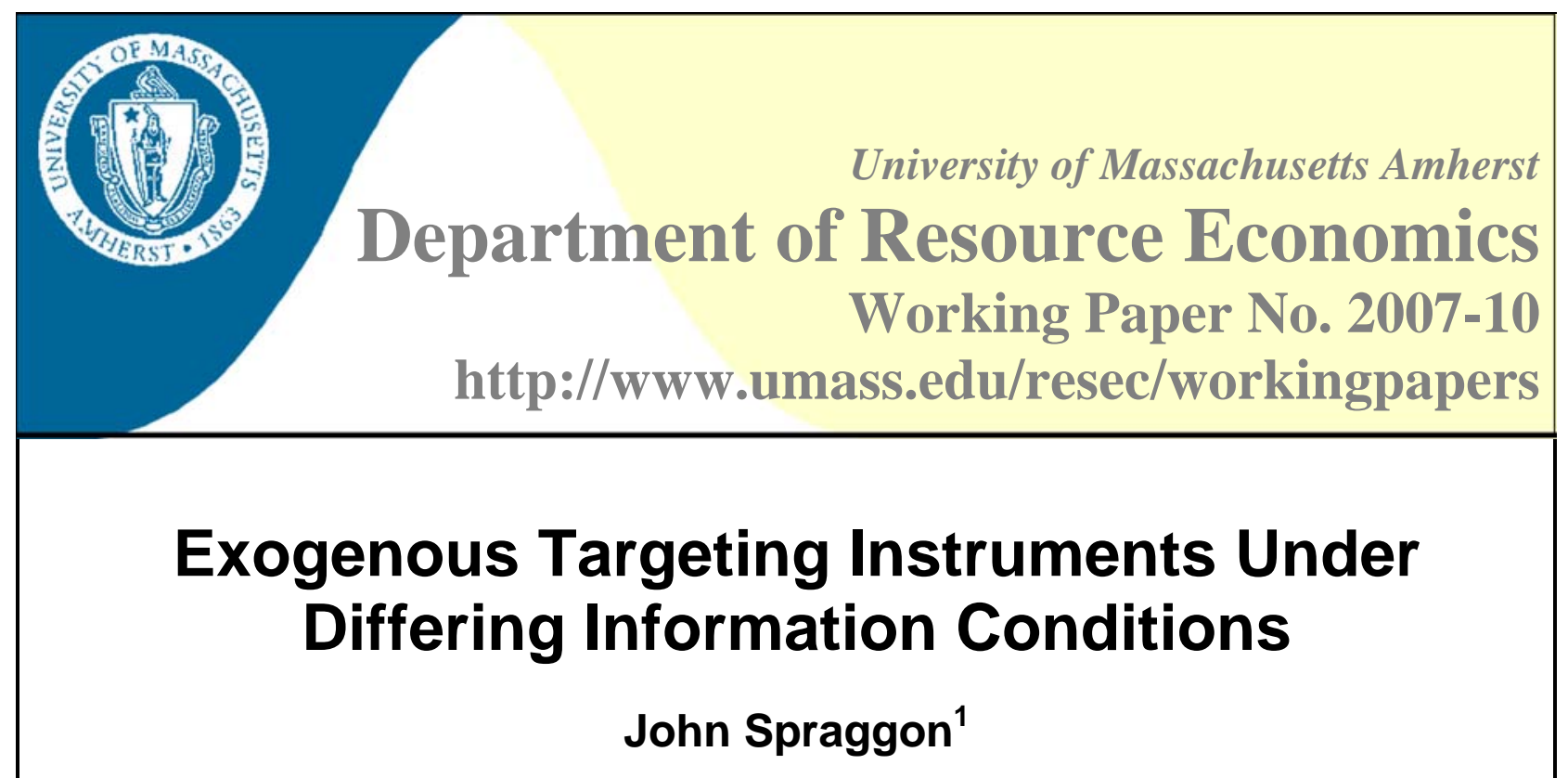

\begin{abstract}
:
This paper tests the ability of an exogenous targeting instrument to induce compliance when the principal cannot observe the actions of individual agents. A number of papers show that although these instruments are able to induce groups to the target outcome, they are not able to induce individuals to make socially optimal decisions in a number of different controlled laboratory experiments. This study investigates whether the information individuals have about others' payoffs affects how they make their decisions in this environment. Ledyard (1995) suggests that when subjects have less information in public goods experiments they are more likely to choose the Nash equilibrium decision. However, as he points out, this effect differs between groups with homogeneous and heterogeneous payoff functions. The results show that reducing information reduces efficiency although there are no significant effects on the absolute level of group decisions at the aggregate level. At the individual level, reducing the information players have complicates the environment resulting in subjects choosing either lower decision numbers or more randomly. Moreover, these effects seem to be more serious for subjects whose Nash decisions are on the boundary of the decision space.
\end{abstract}

Keywords: Moral Hazard in Groups, Exogenous Targeting Instruments, Experiments, Information

JEL Classification: C72, C92, D70

\footnotetext{
${ }^{1}$ John Spraggon, Department of Resource Economics

University of Massachusetts, 212A Stockbridge Hall

80 Campus Center Way, Amherst, MA 01003

E: jmspragg@resecon.umass.edu P: 413-545-6651 F: 413-545-5853
} 


\title{
Exogenous Targeting Instruments under Differing Information Conditions ${ }^{1}$
}

\author{
August 2007 \\ John Spraggon \\ Department of Resource Economics \\ University of Massachusetts Amherst \\ 80 Campus Center Way \\ Amherst, MA \\ 01003 \\ jmspragg@,resecon.umass.edu
}

\begin{abstract}
This paper tests the ability of an exogenous targeting instrument to induce compliance when the principal cannot observe the actions of individual agents. A number of papers show that although these instruments are able to induce groups to the target outcome, they are not able to induce individuals to make socially optimal decisions in a number of different controlled laboratory experiments. This study investigates whether the information individuals have about others' payoffs affects how they make their decisions in this environment. Ledyard (1995) suggests that when subjects have less information in public goods experiments they are more likely to choose the Nash equilibrium decision. However, as he points out, this effect differs between groups with homogeneous and heterogeneous payoff functions. The results show that reducing information reduces efficiency although there are no significant effects on the absolute level of group decisions at the aggregate level. At the individual level, reducing the information players have complicates the environment resulting in subjects choosing either lower decision numbers or more randomly. Moreover, these effects seem to be more serious for subjects whose Nash decisions are on the boundary of the decision space.
\end{abstract}

Keywords: Moral Hazard in Groups, Exogenous Targeting Instruments, Experiments, Information (JEL C72, C92, D70).

\footnotetext{
1 Acknowledgements: This research is sponsored through a grant from the Senate Research Committee at Lakehead University and the Social Science and Humanities Council of Canada (410-2002-0632). Thanks are due to Donna Spraggon for research assistance, Robert Oxoby, and other seminar participants at Wyoming, Laval, Calgary and Windsor.
} 


\section{Introduction}

There are many different situations involving moral hazard in groups. In terms of the worker effort problem, some work groups may have excellent information about the effort of co-workers (sports teams, production shop floors) while some may not (management may not have good information regarding the cost of effort for production floor workers and vice versa). Similarly, some non-point source pollution problems involve very similar polluters with excellent information about each other (dairy farmers). Other situations, however, may involve many different types of polluters (agricultural, industrial and municipal) who may not have good information about each other. For example, Horan (2001) lists ten different non-point source pollution sites in the United States. Of these, at least two involve different types of sources, and two (one of which involves different types of sources) cross state lines. ${ }^{2}$

Many authors discuss and provide refinements to the use of exogenous targeting instruments as theoretical solutions to the moral hazard in groups problem (e.g., Holmstrom 1982, McAfee and McMilan 1991, Segerson 1988 and Xepapadeas 1992, 1995). An exogenous targeting instrument is a contract between a principal and agents, which specifies a threshold level of an observable which is correlated with an unobservable action which the principal wishes the agents to take. For the worker effort problem, the level of output is the observable which is correlated with the agents' unobservable effort level. The principal (owner) specifies a level of output and the agents (workers) receive a bonus or penalty depending upon whether they produce more than the target level of output or not. For the environmental case the ambient level of

\footnotetext{
${ }^{2}$ Specifically, Chesapeake Bay involves both agricultural and urban sources and Dillon Creek involves urban, septic and ski areas.
} 
pollution is often assumed to be the observable which is correlated with the emissions of individual polluters. The principal (environmental regulator) specifies a level of ambient pollution and the agents (polluting firms) receive a penalty if the observed level of pollution exceeds the target and a bonus if it is below (Segerson 1998).

This paper is one in a series that use controlled laboratory experiments to provide empirical evidence as to the efficacy of these instruments. Recent papers by Vossler, et al. (2006), Cochard, et al. (2005), and Spraggon (2002, 2004a) suggest that exogenous targeting instruments are able to induce groups of individuals to comply with a standard under a number of different circumstances. This includes when subjects have heterogeneous payoff functions (Spraggon 2004a) and when subjects are also involved in a market (Vossler, et al. 2006). ${ }^{3}$ However, these instruments are typically unable to induce individuals to make the socially optimal decisions (Spraggon 2004b). The purpose of this experiment is to determine whether the information individuals have influences whether or not their decisions correspond with theoretical predictions.

The experiment discussed here involves two treatment variables: the information condition (full, partial or no information), and the payoff functions (homogeneous or heterogeneous). Under the full information condition subjects know the number of people in their group and everyone's payoff function. This is the information condition under which Spraggon $(2002,2004 a)$ were conducted. Under the partial information condition subjects know the number of people in their group but have no information about the payoff functions of the other people. Under the no information condition subjects only know their own payoff function and have no information about the number

\footnotetext{
${ }^{3}$ Nalbantian and Schotter (1997) investigate a different exogenous targeting instrument which is unable to induce the group to the target outcome.
} 
of people in their group or the payoff functions of the others. This is similar to the information treatment for the threshold public goods experiments investigated in Marks and Croson (1999). ${ }^{4}$ Although there were no significant effects of information at the aggregate level, they observed a greater degree of convergence to the Nash Equilibrium in their incomplete information case than in their full or partial information case. Rondeau, et al. (1999) investigate information in a one-shot provision point game with money back guarantee, a proportional rebate and heterogeneous agents with large groups $(\mathrm{N}=45)$. They also find no significant effects at the aggregate level. As a result, we conjecture that under the no information condition subjects will be more likely to choose the socially optimal decision over time. This should result in greater convergence to the target outcome.

The results are consistent with the results of previous experiments (Ledyard 1995, and Marks and Croson 1999) in that different information conditions have different effects on groups where the subjects have homogenous or heterogeneous payoff functions. Our results suggest the differences here seem to be due to homogenous subjects playing more randomly when they know the number of people in the group but not their payoff functions, and being more likely to choose numbers below the Nash prediction when they have no information. Whereas, heterogeneous subjects play more randomly when they have no information, and are more likely to choose numbers below the Nash prediction when they know the number of people in their group. Thus, reducing information seems to result in more sub-optimal play rather than less. Perhaps more importantly, average decisions converge towards the Nash prediction over time for

\footnotetext{
${ }^{4}$ In Marks and Croson's partial information condition subjects knew the sum of the groups valuation for the public good.
} 
subject types whose decisions are in the decision space but not for those whose Nash decision is on the boundary of their decision space.

\section{The Moral Hazard in Groups Experiment}

The design of the experiment is based on a standard model of non-point source pollution used by Segerson (1988), Malik (1990) and Xepapadeas (1995) and reported in Spraggon (2002). ${ }^{5}$ Subjects' decisions are assumed to impose an externality on society. The larger the decision number the larger the externality and the higher the subject's payoff up to some maximum decision number. This part of the subject's payoff is described as their private payoff and is provided to the subjects in a table. ${ }^{6}$ It can be described by the following function:

$$
B_{n}\left(x_{n}\right)=25-0.002\left(x_{n}^{\max }-x_{n}\right)^{2}
$$

where $B_{n}$ is the benefit function, $x_{n}$ is the decision number, $x_{n}{ }^{\max }$ is the maximum decision number and $n$ indexes the individual subjects $(n=1 . .6)$. This functional form and the parameters where chosen for mathematical convenience.

The primary research question is whether the instruments suggested by Segerson (1988) are able to induce individuals to reduce a decision number to the socially optimal level. We look at one specific form of the instrument suggested by Segerson: The tax/subsidy instrument taxes or provides a subsidy to everyone in the group depending on the difference between the target aggregate group decision number and the actual group decision number. We refer to the aggregate group decision number as the group total.

\footnotetext{
${ }^{5}$ Nalbantian and Schotter's (1997) experiment was also used as a model specifically for the number of subjects per group and number of periods per session. This experiment differs from Nalbantian and Schotter's in terms of being framed as a public bad rather than a public good. See Park (2001) for a comparison of these frameworks.

${ }^{6}$ See the instructions included in the appendix.
} 
The instrument is a linear function of the difference between the actual and the target group totals.

$$
T(X)=0.3(X-150)
$$

where $\mathrm{T}(X)$ is the group benefit function, $X$ is the aggregate decision number (or group total $\left.X=\sum_{n=1}^{6} x_{n}\right), 150$ is the target and 0.3 is the tax and subsidy rate. As a result each subject faces the following payoff function:

$$
\Pi_{n}=25-0.002\left(x_{n}^{\max }-x_{n}\right)^{2}-0.3\left(\sum_{n=1}^{6} x_{n}-150\right) .
$$

This payoff function has a unique maximum at: $x_{n}^{*}=x_{n}^{\max }-75$. Thus, the payoff maximizing decision is for each subject to reduce their decision number from their maximum by seventy-five.

There are three different subject types. For the homogeneous sessions all six of the subjects are medium capacity: $x_{n}{ }^{\max }=100, x_{n}{ }^{*}=25$. For the heterogeneous sessions three of the six subjects are large capacity: $x_{n}{ }^{m a x}=125, x_{n}{ }^{*}=50$ and three are small capacity subjects: $x_{n}{ }^{m a x}=75, x_{n}{ }^{*}=0$. It is important to notice that in the experiment subjects were constrained to choose numbers between 0 and $x_{n}{ }^{\max }$. As a result while large and medium capacity subjects can choose numbers above or below the theoretical prediction small capacity subjects are only able to choose numbers above the theoretical prediction.

There is also a group optimal solution under this instrument. If all subjects choose zero the payoff of the group is maximized. This is not a Nash equilibrium as it is in each individual's best interest to reduce their decision number from the maximum by seventy-five. 
The level of information subjects have about the number and payoffs of other people in the group is the treatment variable of interest in this paper. We investigate three different cases: full information, partial information and no information. In all three cases subjects know their own payoff functions. Under the full information condition subjects know the number of other subjects in their group as well as the payoffs of the others in their group. Under the partial information condition subjects know how many people are in their group but do not have information about other's payoffs. Under the no information condition subjects know neither the number of people in their group nor the payoffs of the others.

This experiment is concerned with data from two separate sources. Data for the full information treatment was collected at one university while the data for the partial and no information treatments were collected at a second university. ${ }^{7}$ The procedures used to conduct the sessions were identical except for the information provided to subjects (the treatment variable) and the fact that a session at the first university consisted of one group of six subjects while a session at the second university consisted of two groups of six subjects. This was done so that if subjects assumed the other people in the room comprised their group in the no information conditions, dividing the target by the number of people in the room would not be the Nash equilibrium. As a result of the separate sources for the full information, and no and partial information data emphasis is placed on comparing the treatments with theoretical prediction rather than comparing across treatments.

\footnotetext{
${ }^{7}$ The names of the universities have been suppressed to protect the anonymity of the authors.
} 


\section{Theoretical Predictions}

The primary questions addressed by this study concern the average level of aggregate decision number (group total). The purpose of these exogenous targeting instruments is to reduce the ambient level of pollution to the target level. As a result, the first hypothesis concerns the ability of this instrument to reduce the group total to the target level for each of the treatments. A secondary concern is whether this instrument is able to induce individuals to reduce their emissions to the optimal level.

Hypothesis 1: The Tax/Subsidy Instrument will be able to induce the group to the target outcome independent of the information condition.

The Tax/Subsidy instrument induces the optimal decision as a dominant strategy regardless of the information that subjects have. Indeed the less information they have about other subjects the more likely they should be to concentrate on their own payoff function. Moreover, the Tax/Subsidy instrument is designed such that the larger the deviation from the target outcome the larger the fine and as a result the more likely that subjects will go bankrupt and be removed from the group, thereby reducing the group total.

Hypothesis 2: Less information will result in subjects' decisions being closer to the Nash decision.

This hypothesis comes from the results of the Marks and Croson (1999) study. As discussed in the introduction, they found that although on average there was no difference across the information conditions they did find greater convergence to the Nash equilibrium in the treatments with less information. If this result transfers over into this environment we should observe similar convergence to both the target at the aggregate level and the Nash decision numbers at the individual level. 
There are many reasons why decisions may diverge from the Nash equilibrium. We are primarily concerned with subjects' preferences differing from payoff maximization, and subjects' decisions being affected by random error. We expect that when information is removed either the experimental environment becomes simpler and so the degree of error is reduced or the reduction in information changes the subjects preferences (for example if you do not know that your contributions will benefit 10 other people you may not receive as much utility through altruism as if you did have this information) ${ }^{8}$

\section{Results}

The results are separated into five sections. The first two results deal with the aggregate decision numbers at the session level and show broadly that information does not affect the ability of exogenous targeting instruments to induce groups to choose the target outcome. Next we look at the convergence properties of the aggregate data and find some evidence for greater convergence with no information when subjects are heterogeneous but not when subjects are homogeneous in terms of their payoff functions. Results 4 and 5 look at the means and convergence of the data at the individual level. Again the results vary by information and heterogeneity but the results of the small capacity subjects, for whom the theoretically predicted decision lies on the boundary of their decision space, differ systematically from the other two subject types.

Result 1: Information has no effect on the aggregate decision number.

Table 1 suggests that aggregate decision numbers for heterogeneous groups significantly exceed the target level (at the 10\% significance level) for both the no information and full

\footnotetext{
${ }^{8}$ See Goeree, et al. (2002) for a detailed discussion of altruism.
} 
information treatment. For the partial information with heterogeneity treatment we also observe aggregate decision numbers which exceed the target on average but the variance is too high to support the hypothesis that the average exceeds the target. ${ }^{9}$ This is consistent with previous results (Marks and Croson 1999) which suggest that information does not effect the data at the aggregate level, but inconsistent with hypothesis 2 .

Table 1: Mean Group Total by Treatment

\begin{tabular}{lccc}
\hline & No Information & $\begin{array}{c}\text { Partial } \\
\text { Information }\end{array}$ & $\begin{array}{c}\text { Full } \\
\text { Information }\end{array}$ \\
\hline Heterogeneous & $196.63^{*}$ & 174.69 & $170.47^{*}$ \\
& 12.19 & 23.03 & 6.62 \\
& 3 & 3 & 3 \\
Homogeneous & 150.80 & 174.51 & 158.44 \\
& 7.78 & 17.65 & 7.70 \\
& 3 & 3 & 3 \\
\hline
\end{tabular}

Each cell contains mean, standard error and frequency. An * indicates that the Group Total is significantly different from 150 at the $10 \%$ level.

Figures 1 and 2 show the average group totals over the three sessions in each cell. Notice that both for heterogeneous (Figure 1) and homogeneous (Figure 2) groups there is not much difference between the lines representing the average group total in any of the periods.

This supports Hypothesis 1 in that the information that individuals have about the other participants under the tax/subsidy instrument does not have any significant effects on the ability of this instrument to reduce the aggregate decision number to the target.

\footnotetext{
${ }^{9}$ The statistical analysis here is based on a standard t-test using the standard error calculated across the mean values from the three sessions in each cell. For heterogeneous groups p-value for the test that the mean is not equal to 150 is $0.0620,0.3958$ and 0.0906 for no, partial and full information respectively.
} 
Result 2: There are reductions in efficiencies due to both heterogeneity and information.

Efficiency is defined as the change in the value of the social planner's problem as a percentage of the optimal change in the social planner's problem. In this experiment the social planner's problem is to maximize the producer's payoffs minus the social cost of pollution:

$$
S P=\max \sum_{n=1}^{6} 25-0.002\left(x_{n}^{\max }-x_{n}\right)^{2}-0.3\left(\sum_{n=1}^{6} x_{n}\right) .
$$

Efficiency is then given by:

$$
E=\frac{S P_{\text {Actual }}-S P_{\text {StatusQuo }}}{S P_{\text {Optimal }}-S P_{\text {StatusQuo }}}
$$

where $S P_{\text {Actual }}$ is the actual value of the social planner's problem given the choices of the subjects, $S P_{\text {StatusQuo }}$ is the value of the social planner's problem if all of the subjects choose their maximum decision $\left(x_{n}{ }^{m a x}\right)$ and $S P_{\text {Optimal }}$ is the value of the social planner's problem if all of the subjects choose their optimal decision $\left(x_{n}{ }^{*}\right)$. The value of efficiency ranges between 0 and 1 and is represented in Table 2 as a percentage. Notice that there are real differences in efficiency across the treatments. The heterogeneous groups have lower efficiencies and no and partial information sessions have lower efficiencies than the full information sessions. Also notice that heterogeneous groups have lower efficiencies under the no information condition while homogeneous groups have the lowest efficiency under partial information.

The differences in efficiency which are not observed in the group total can be explained by variability in the individual decisions and the fact that efficiency takes into account the costs of reducing the decision number. Thus a heterogeneous group who all choose 25 would have a group total of 150 but an efficiency of 88.9. Clearly both 
heterogeneity and reductions in information reduce efficiency. Moreover, we observe different effects of information on groups with homogeneous and heterogeneous payoff functions as observed for public goods (Ledyard 1995).

Table 2: Mean Efficiencies by Treatment

\begin{tabular}{ccccc}
\hline & No Info & Information & & \\
& Partial Info & Full Info & Total \\
\hline Heterogeneous & $79.68 \%$ & $82.41 \%$ & $85.09 \%$ & $82.39 \%$ \\
& 2.80 & 0.62 & 4.88 & 1.81 \\
& 3 & 3 & 3 & 9 \\
Homogeneous & $89.16 \%$ & $86.94 \%$ & $96.33 \%$ & $90.81 \%$ \\
& 0.79 & 2.84 & 1.09 & 1.68 \\
Total & 3 & 3 & 3 & 9 \\
& $84.42 \%$ & $84.68 \%$ & $90.71 \%$ & $86.60 \%$ \\
& 2.49 & 1.65 & 3.36 & 1.57 \\
& 6 & 6 & 6 & 18 \\
\hline
\end{tabular}

Each cell contains the efficiency as a percentage, standard deviation and frequency.

Result 3: Convergence of the group total differs across treatment.

Marks and Croson (1999) use a random effects regression with period and period squared to show greater convergence to the Nash outcome for their aggregate data. We combine this model with an asymptotic convergence model suggested by Noussair, et al. (1995). The Noussair, et al. asymptotic model uses the inverse of period to estimate the asymptotic starting value and (period-1)/period to estimate the asymptotic ending value. Thus the model we estimate for each treatment is:

$$
\text { Group Total }_{i t}=\beta_{1} t_{i}+\beta_{2} t_{i}^{2}+\beta_{3}\left(1 / t_{i}\right)+\beta_{4}\left(t_{i}-1\right) / t_{i}+u_{i}+\epsilon_{i t} \text {. }
$$

where $\mathrm{i}$ indexes the group and $\mathrm{t}$ indexes the period, $\mathrm{u}_{\mathrm{i}}$ is a group specific error term and $\epsilon_{\text {it }}$ is the standard error term. 
Table 3 presents the estimated coefficients from these regressions. Figures 3 and 4 depict the average decision, the prediction from the regression model and the confidence intervals based on the standard error from the regressions for each of the treatments. Figure 3 presents these results for the heterogeneous groups. Notice that aggregate decision is converging to the target in terms of both level and variance for the no information treatment. However, aggregate decisions for the partial and full information treatments are both rising and becoming more variable over time. Table 4, which presents the actual and predicted average group total for period 1 and period 25, confirms these observations. Figure 4 presents these results for homogeneous groups. Among homogeneous groups aggregate decisions are very similar to the target. The full information sessions have the lowest variance at the end of the session. Table 4 confirms this and suggests that the variances are not much different between the heterogeneous and homogeneous sessions.

Thus, our results are consistent with Marks and Croson (1999) who find greater convergence in their incomplete information case for the heterogeneous case. However, this result does not carry over to the case where subjects are homogeneous in terms of their payoffs..$^{10}$

\footnotetext{
${ }^{10}$ Marks and Croson (1999) only investigate groups with heterogeneous endowments.
} 
Table 3: Combined Model

\begin{tabular}{|c|c|c|c|c|c|c|}
\hline & \multicolumn{3}{|c|}{ Heterogeneous } & \multicolumn{3}{|c|}{ Homogeneous } \\
\hline & No Info & $\begin{array}{l}\text { Partial } \\
\text { Info }\end{array}$ & Full Info & No Info & $\begin{array}{l}\text { Partial } \\
\text { Info }\end{array}$ & Full Info \\
\hline Observations & 75 & 75 & 75 & 75 & 75 & 75 \\
\hline Prob $>X^{2^{*}}$ & 0.0000 & 0.0000 & 0.0000 & 0.0000 & 0.000 & 0.000 \\
\hline \multirow{2}{*}{ Period } & -0.272 & 2.73 & -5.65 & -10.29 & 3.30 & -3.74 \\
\hline & (5.89) & (11.27) & $(6.60)$ & (6.09) & (4.14) & $(4.23)$ \\
\hline \multirow{4}{*}{ Period $^{2}$} & 0.963 & 0.809 & 0.392 & 0.075 & 0.426 & 0.376 \\
\hline & -0.104 & -0.048 & 0.234 & 0.367 & -0.136 & 0.123 \\
\hline & $(0.126)$ & $(0.362)$ & $(0.279)$ & $(0.210)$ & $(0.101)$ & $(0.145)$ \\
\hline & 0.411 & 0.894 & 0.403 & 0.051 & 0.176 & 0.396 \\
\hline \multirow{3}{*}{$\frac{1}{\text { Period }}$} & 148.69 & 181.30 & 133.71 & 107.95 & 143.67 & 160.49 \\
\hline & (3.84) & $(46.42)$ & $(9.62)$ & $(37.82)$ & $(27.81)$ & $(41.81)$ \\
\hline & 0.000 & 0.000 & 0.000 & 0.000 & 0.000 & 0.000 \\
\hline \multirow{3}{*}{$\frac{(\text { Period }-1)}{\text { Period }}$} & 236.45 & 144.33 & 202.81 & 220.52 & 165.05 & 183.37 \\
\hline & (75.09) & (59.99) & $(34.07)$ & $(40.02)$ & $(33.01)$ & $(28.91)$ \\
\hline & 0.0000 & 0.016 & 0.000 & 0.000 & 0.000 & 0.0000 \\
\hline
\end{tabular}

Group Total ${ }_{i t}=\beta_{1}\left(1 / t_{i}\right)+\beta_{2}\left(t_{i}-1\right) / t_{i}+\beta_{3} t_{i}+\beta_{4} t_{i}^{2}+u_{i}+\epsilon_{i t}$. Each cell contains the estimated coefficient, standard error and $\mathrm{p}$-value. ${ }^{*}$ Prob $>\mathrm{X}^{2 *}$ is the $\mathrm{p}$-value for the joint test that all of the coefficients are equal to zero.

[Table 4 about here]

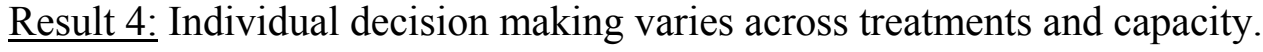

Recall that equation (3) suggests that there is a unique payoff maximizing dominant strategy for each of the subject types. This predicts that large capacity subjects will choose 50 , medium capacity subjects will choose 25 and small capacity subjects will choose 0 . Table 5 reports the mean, median, standard error and frequency of the decision numbers by subject type across information treatment. Notice that the decision numbers are lower than the payoff maximizing decision number for large and higher for the small capacity subjects in all cases.

Also notice in table 5 that the medians for large capacity subjects are well below the prediction, medians are below for the medium capacity subjects expect under full information where they are equal to the prediction and medians are above the prediction 
for small capacity subjects. This suggests that for the homogeneous groups, subjects choose slightly lower numbers with less information, while for heterogeneous groups the decision numbers are lower under partial information than they are under full information but are slightly higher under no information.

Table 5: Average and Median Decisions by Treatment

\begin{tabular}{|c|c|c|c|c|c|c|}
\hline \multirow[t]{2}{*}{ Subject Type } & \multicolumn{2}{|c|}{$\begin{array}{c}\text { No } \\
\text { Information }\end{array}$} & \multicolumn{2}{|c|}{ Partial Information } & \multicolumn{2}{|c|}{ Full Information } \\
\hline & Mean & Median & Mean & Median & Mean & Median \\
\hline Large & $\begin{array}{c}41.67^{*} \\
(2.18) \\
185\end{array}$ & 33 & $\begin{array}{c}41.42^{*} \\
(2.37) \\
218\end{array}$ & 25 & $\begin{array}{c}35.29^{*} \\
(1.57) \\
225\end{array}$ & 30 \\
\hline Medium & $\begin{array}{c}25.13 \\
(1.17) \\
450\end{array}$ & 20 & $\begin{array}{c}29.08 \\
(1.26) \\
450\end{array}$ & 20 & $\begin{array}{c}26.41 \\
(0.674) \\
450\end{array}$ & 25 \\
\hline Small & $\begin{array}{c}30.84^{*} \\
(1.64) \\
225\end{array}$ & 25 & $\begin{array}{c}17.71^{*} \\
(1.29) \\
225\end{array}$ & 19 & $\begin{array}{c}21.53^{*} \\
(1.41) \\
225\end{array}$ & 20 \\
\hline
\end{tabular}

Each cell in the Mean columns contain the mean of subjects decision number, standard error and number of observations. Decisions of subjects who were bankrupt were eliminated. An * indicates that the mean differs from the Nash prediction at the $5 \%$ level.

Distributions of individual decisions are presented in Figures 5, 6, and 7 for large, medium and small capacity subjects respectively. For the large capacity subjects (Figure 5) notice that for all treatments, most of the decisions are well below the Nash prediction. There is a larger peak under full information at 25 and under partial information at 14 , while decisions seem to be much more random under no information. For the medium capacity subjects (Figure 6) the obvious peak at the Nash prediction under full information is noticeably absent under no and partial information. For medium capacity subjects under both no and partial information, the modal decision falls to zero. Notice for medium capacity subjects decisions seem to be more random under partial 
information. For the small capacity subjects (Figure 7) the modal decision is zero in all three treatments but the peak is highest for partial information and almost non-existent under no information. Thus subjects with heterogeneous payoff functions (large and small capacity) behave more randomly when they have no information, while the subjects with homogeneous payoff functions behave more randomly when they know the number of people in the group but not their payoff functions (partial information).

Result 5: Convergence in Individual Decisions.

Next we address whether the decision numbers converge towards the Nash decision over time. Table 6 presents the combined convergence model discussed for aggregate decisions in Result 3, estimated by subject type and information on the individual decisions:

$$
\text { Decision }_{i t}=\beta_{1}\left(1 / t_{i}\right)+\beta_{2}\left(t_{i}-1\right) / t_{i}+\beta_{3} t_{i}+\beta_{4} t_{i}^{2}+u_{i}+\epsilon_{i t}
$$

where $\mathrm{i}$ indexes subject, $\mathrm{t}$ indexes period, $\mathrm{u}_{\mathrm{i}}$ is the individual specific random effect and $\mathrm{C}_{\mathrm{it}}$ is the standard error term. Figures 8 through 10 show the time series of average decisions, the prediction and the confidence interval based on the regression for each treatment. Figure 8 shows that for large capacity subjects all of the treatments are generally close to the theoretical prediction. Decisions seem to be converging towards the Nash prediction for full and partial information. For partial information, variance seems to be rising over time. For no information decisions are generally below the theoretical prediction for large capacity subjects. Table 7 presents actual and predicted average decision and standard errors by treatment for periods 1 and 25. Standard errors are generally larger under the partial information treatment but there is no indication that 
they are smaller under full information than they are under no information. Figure 9

shows that the decisions of medium capacity subjects are generally close to the Nash

prediction with the variance being higher in both the no and partial information

treatments. Table 7 confirms that the variances are smaller under full information than

they are under the other two information conditions for medium capacity subjects. Figure

10 shows that the decisions of small capacity subjects are always well above the

prediction and there is no indication of convergence towards this prediction in any of the

information treatments. Table 7 suggests that the decision numbers are generally higher

under no information and variance is a bit smaller under partial information.

Table 6: Asymptotic Convergence for Individual Decisions

\begin{tabular}{cccccccccc}
\hline & \multicolumn{3}{c}{ Large Capacity } & \multicolumn{3}{c}{ Small Capacity } & \multicolumn{3}{c}{ Medium Capacity } \\
& No Info & $\begin{array}{c}\text { Partial } \\
\text { Info }\end{array}$ & $\begin{array}{c}\text { Full } \\
\text { Info }\end{array}$ & $\begin{array}{c}\text { No } \\
\text { Info }\end{array}$ & $\begin{array}{c}\text { Partial } \\
\text { Info }\end{array}$ & $\begin{array}{c}\text { Full } \\
\text { Info }\end{array}$ & No Info & $\begin{array}{c}\text { Partial } \\
\text { Info }\end{array}$ & $\begin{array}{c}\text { Full } \\
\text { Info }\end{array}$ \\
\hline Observations & 185 & 218 & 225 & 225 & 225 & 225 & 450 & 450 & 450 \\
Prob $>X^{2^{*}}$ & 0.0000 & 0.0000 & 0.0000 & 0.0000 & 0.0000 & 0.0027 & 0.0000 & 0.000 & 0.000 \\
& 0.31 & 3.36 & -0.484 & -0.24 & -3.06 & -1.39 & -1.71 & 0.55 & -0.62 \\
Period & $(2.06)$ & $(1.56)$ & $(1.10)$ & $(1.90)$ & $(0.98)$ & $(0.980)$ & $(0.94)$ & $(0.66)$ & $(0.79)$ \\
& 0.881 & 0.031 & 0.660 & 0.900 & 0.002 & 0.153 & 0.068 & 0.402 & 0.430 \\
Period $^{2}$ & -0.03 & -0.75 & 0.038 & 0.01 & 0.09 & 0.04 & 0.06 & -0.02 & 0.02 \\
& $(0.07)$ & $(0.04)$ & $(0.04)$ & $(0.06)$ & $(0.03)$ & $(0.04)$ & $(0.03)$ & $(0.02)$ & $(0.02)$ \\
& 0.677 & 0.041 & 0.381 & 0.836 & 0.004 & 0.313 & 0.059 & 0.271 & 0.361 \\
1 & 26.00 & 41.60 & 19.58 & 23.81 & 19.06 & 24.99 & 17.99 & 23.95 & 26.75 \\
Period & $(8.64)$ & $(9.77)$ & $(4.20)$ & $(6.84)$ & $(6.63)$ & $(8.63)$ & $(3.47)$ & $(5.49)$ & $(4.64)$ \\
& 0.003 & 0.000 & 0.000 & 0.000 & 0.004 & 0.004 & 0.000 & 0.000 & 0.000 \\
$($ Period-1) & 44.07 & 9.48 & 35.58 & 32.69 & 41.71 & 32.03 & 36.75 & 27.51 & 30.56 \\
Period & $(11.73)$ & $(16.20)$ & $(6.25)$ & $(14.42)$ & $(10.59)$ & $(9.06)$ & $(6.00)$ & $(6.92)$ & $(6.39)$ \\
& 0.0000 & 0.558 & 0.000 & 0.023 & 0.000 & 0.000 & 0.000 & 0.000 & 0.000 \\
\hline Decision
\end{tabular}

Decision $_{\mathrm{it}}=\beta_{1}\left(1 / \mathrm{t}_{\mathrm{i}}\right)+\beta_{2}\left(\mathrm{t}_{\mathrm{i}}-1\right) / \mathrm{t}_{\mathrm{i}}+\beta_{3} \mathrm{t}_{\mathrm{i}}+\beta_{4} \mathrm{t}_{\mathrm{i}}^{2}+\mathrm{u}_{\mathrm{i}}+\epsilon_{\mathrm{it}}$. Each cell contains the estimated coefficient, standard error and $\mathrm{p}$-value. ${ }^{*}$ Prob $>\mathrm{X}^{2^{*}}$ is the $\mathrm{p}$-value for the joint test that all of the coefficients are equal to zero.

[Table 7 about here]

That large capacity subjects consistently reduce their decision numbers below the Nash predictions is concerning as it results in these subjects experiencing more 
bankruptcies (Table 8, and the number of non-bankruptcy observations for large capacity subjects (185 for no and 218 for partial information)).

This inequality also appears in the final or cumulative payoffs. Table 9 presents these cumulative payoffs by information and subject capacity. ${ }^{11}$ Notice that under the no information condition, the medium capacity subjects make more profit than both the large and the small capacity subjects, while in the other two cases the small capacity subjects make the highest payoffs at the expense of the large capacity subjects. This coupled with the observation that small capacity subjects are much more likely to choose the Nash equilibrium decision (0) under partial information is an interesting result. When heterogeneous subjects have no information they seem to play more randomly, when they know the number of people in their group (but nothing about payoffs) all subjects seem to be more likely to choose lower decisions and indeed the Nash decision in the small capacity subjects case. Whereas, homogeneous subjects seem to be more likely to choose lower decision numbers under the no information treatment and play more randomly in the partial information condition.

\section{Table 8: Bankruptcies by Session}

\begin{tabular}{ccccc}
\hline & No Info & $\begin{array}{c}\text { Information } \\
\text { Partial Info }\end{array}$ & Full Info & Total \\
\hline Heterogeneous & 40 & 7 & 0 & 47 \\
& 450 & 450 & 450 & 1350 \\
Homogeneous & 0 & 0 & 0 & 0 \\
& 450 & 450 & 450 & 1350 \\
Total & 40 & 7 & 0 & 47 \\
& 900 & 900 & 900 & 2700 \\
\hline
\end{tabular}

Each cell contains the number of subject decision periods where subjects were bankrupt for each treatment, and the total number of subject decision periods.

\footnotetext{
${ }^{11}$ Subjects were also paid a $\$ 5(\mathrm{Cdn}$.) show up fee but this amount is excluded from the payoffs reported in Table 9.
} 
Table 9 Cumulative Payoffs (in Canadian Dollars) by Session

\begin{tabular}{ccccc}
\hline Subject Type & No Information & $\begin{array}{c}\text { Partial } \\
\text { Information }\end{array}$ & $\begin{array}{c}\text { Full } \\
\text { Information }\end{array}$ & Total \\
\hline \multirow{2}{*}{ Large } & 6.10 & 8.18 & 7.29 & 7.34 \\
& 4.068 & 4.036 & 3.258 & 3.642 \\
& 5 & 8 & 9 & 22 \\
Medium & 13.96 & 10.10 & 13.267 & 12.44 \\
& 2.989 & 5.164 & 2.060 & 3.957 \\
& 18 & 18 & 18 & 54 \\
Small & 9.94 & 12.68 & 13.91 & 12.18 \\
& 3.050 & 6.251 & 2.707 & 3.957 \\
& 9 & 9 & 9 & 27 \\
\hline
\end{tabular}

Each cell contains the mean cumulative payoff, standard deviation and number of observations.

\section{Conclusions}

Even though information has no effect on the aggregate decision number it does have an adverse effect on efficiency in a controlled laboratory moral hazard in group experiment. These effects of efficiency signal effects of information on individual decision making. For subjects with heterogeneous payoff functions, partial information (knowing the number of subjects in the group but not their payoffs) results in subjects playing lower decision numbers, while having no information results in heterogeneous subjects playing more randomly. The reverse is true for homogeneous subjects. They seem to choose lower numbers than predicted under no information and play more randomly under partial information. This differential effect is consistent with previous experimental results (Ledyard 1995) and goes a step towards providing an explanation for the observed differences in outcome. The results also show that decisions adjust towards the Nash prediction except for small capacity subjects whose theoretically predicted decision is on the boundary of their decision space. 
Clearly, the results suggest the importance of participants in an Exogenous Targeting Instrument regime being fully informed of how they are expected to behave and the consequences from deviating from this behaviour. Moreover, steps must be taken to ensure that firms are unable to use these instruments in order to impose significant monetary costs on their competitors by not complying when their competitors choose to do so.

The results are also suggestive that subjects find this environment very challenging and when the potential to use simple heuristics are removed they play more randomly or risk aversely. This suggests future work in which the instructions are clearer with respect to the purpose of the instrument. Moreover, it may prove worthwhile to investigate the expectations that subjects have as to the decisions of the other members of their groups.

\section{References}

Anderson, Simon, Jacob Goeree, and Charles Holt, 1998. "A Theoretical Analysis of Altruism and Decision Error in Public Goods Games." Journal of Public Economics, 70 (2), 297-323.

Andreoni, James, 1995. "Warm Glow versus Cold-Prickle: The Effects of Positive and Negative Framing on cooperation Experiment", Quarterly Journal of Economics, 110, 122.

Brown, M. B. and A. B. Forsythe, 1974. "Robust test for the equality of variances." Journal of the American Statistical Association 69, 364-367.

Camerer, Colin, 2003. Behavioral Game Theory. Princeton University Press.

Cochard, François, Marc Willinger and Anastasios Xepapadeas, 2005. "Efficiency of Nonpoint Source Pollution Instruments with Externality among Polluters: An Experimental Study." Environmental and Resource Economics, 30, 393-422.

Goeree, Jacob, K., Charles A. Holt and Susan K. Laury, 2002. "Private costs and public benefits: unravelling the effects of altruism and noisy behaviour." Journal of Public Economics, 83, 255-276. 
Holmstrom, B., 1982. "Moral Hazard in Teams." Bell Journal of Economics, 13, 324340 .

Horan, R.D., 2001. "Differences in Social and Public Risk Perceptions and Conflicting Impacts on Point/Nonpoint Trading Ratios", American Journal of Agricultural Economics, 83, 934-941.

Ledyard, John O., 1995. "Public Goods: A Survey of Experimental Research." The Handbook of Experimental Economics, eds. John Kagel and Alvin Roth, Princeton University Press, Princeton NJ.

Levene, H. 1960, "Robust tests for equality of variances." Contributions to Probability and Statistics, ed. I. Olkin, 279-292. Stanford University Press, California.

Malik, Arun, 1990. "Markets for Pollution Control when firms are Noncompliant." Journal of Environmental Economic Management, 18, 97-106.

Marks, Melanie B. and Rachel T.A. Croson, 1999. "The effect of incomplete information in a threshold public goods experiment." Public Choice, 99, 103-118.

McAfee, P. R., and J. McMillan, 1991. "Optimal contracts for teams." International Economic Review, 32(3), 561-577.

Nalbantian, Haig and Andrew Schotter, 1997. "Productivity Under Group Incentives: An Experimental Study." American Economic Review, June 1997, 87, 314-41

Noussair, C.N., Plott, C.R., and R.G., Riezman, 1995. “An Experimental Investigation of the Patterns of International Trade." American Economic Review, 85, 462-491.

Park, Eun-Soo, 2001. "Warm-Glow versus Cold-Prickle: A Further Experimental Study of Framing Effects on Free-Riding." Journal of Economic Behavior and Organization, $43,4,405-421$.

Rondeau, Daniel, William D. Schulze and Gregory L. Poe, 1999. "Voluntary revelation of the demand for public goods using a provision point mechanism." Journal of Public Economics, 72, 455-470.

Rose, Steven K., Jeremy Clark, Gregory L. Poe, Daniel Rondeau and William D. Schulze, 2002. "The private provision of public goods: tests of a provision point mechanism for funding green power programs." Resource and Energy Economics, 24, $131-151$.

Segerson, Kathleen, 1988. "Uncertainty and incentives for nonpoint pollution control." Journal of Environmental Economic Management, 15, 87-98. 
Shortle, James S. and Richard D. Hoarn, 2001. "The Economics of Nonpoint Pollution Control.” Journal of Economic Surveys, 15(3), 255-289.

Sonnemans, Joep, Arthur Schram., and Theo Offerman, 1998. "Public Good Provision and Public Bad Prevention: The Effect of Framing." Journal of Economic Behavior and Organization, 34, 143-161.

Spraggon, John, 2002. "Exogenous Targeting Instruments as a Solution to Group Moral Hazard. Journal of Public Economics, 84(3), 427-456.

Spraggon, John, (2004a). "Exogenous Targeting Instruments with Heterogeneous Agents." Journal of Environmental Economics and Management, 48, 837-856.

Spraggon, John, (2004b). "Individual Decision Making in a Negative Externality Experiment." Experimental Economics, 7(3), 249-269.

Vossler, Christian A, Gregory L. Poe, Kathy Segerson, and William D. Schulze, 2006. "Communication and incentive mechanisms based on group performance: An experimental study of nonpoint pollution control.” Economic Inquiry, 44(4), 599-613.

Xepapadeas, A. P., 1992. "Environmental Policy Design and Dynamic Nonpoint-Source Pollution." Journal of Environmental Economics and Management, 22, 22-39.

Xepapadeas, A. P., 1995. "Observability and choice of instrument mix in the control of externalities" Journal of Public Economics, 56, 485-498. 
Table 4: Predicted and Actual Aggregate Decisions by Treatment, Period 1 and Period 25.

\begin{tabular}{|c|c|c|c|c|c|c|c|c|c|c|c|c|}
\hline & \multicolumn{6}{|c|}{ Homogeneous } & \multicolumn{6}{|c|}{ Heterogeneous } \\
\hline & \multicolumn{2}{|c|}{ No Information } & \multicolumn{2}{|c|}{$\begin{array}{c}\text { Partial } \\
\text { Information }\end{array}$} & \multicolumn{2}{|c|}{ Full Information } & \multicolumn{2}{|c|}{ No Information } & \multicolumn{2}{|c|}{$\begin{array}{c}\text { Partial } \\
\text { Information }\end{array}$} & \multicolumn{2}{|c|}{ Full Information } \\
\hline & Actual & Predicted & Actual & Predicted & Actual & Predicted & Actual & Predicted & Actual & Predicted & Actual & Predicted \\
\hline $\begin{array}{c}\text { Period } \\
1\end{array}$ & $\begin{array}{c}108 \\
(36.96)\end{array}$ & $\begin{array}{c}98.03 \\
(35.95)\end{array}$ & $\begin{array}{c}150 \\
(28.58)\end{array}$ & $\begin{array}{l}146.83 \\
(28.42)\end{array}$ & $\begin{array}{c}160 \\
(39.88)\end{array}$ & $\begin{array}{l}158.88 \\
(45.53)\end{array}$ & $\begin{array}{c}149 \\
(3.93)\end{array}$ & $\begin{array}{l}148.31 \\
(8.64)\end{array}$ & $\begin{array}{c}195 \\
(41.10)\end{array}$ & $\begin{array}{l}183.99 \\
(45.15)\end{array}$ & $\begin{array}{c}136 \\
(7.77)\end{array}$ & $\begin{array}{l}128.30 \\
(10.54)\end{array}$ \\
\hline $\begin{array}{l}\text { Period } \\
25\end{array}$ & $\begin{array}{c}166 \\
(52.14)\end{array}$ & $\begin{array}{l}188.47 \\
(23.24)\end{array}$ & $\begin{array}{c}150 \\
(55.51)\end{array}$ & $\begin{array}{l}161.37 \\
(31.84)\end{array}$ & $\begin{array}{c}197 \\
(20.74)\end{array}$ & $\begin{array}{l}165.83 \\
(16.52)\end{array}$ & $\begin{array}{c}184^{*} \\
(10.40)\end{array}$ & $\begin{array}{l}161.40 \\
(11.93)\end{array}$ & $\begin{array}{c}169 \\
(47.42)\end{array}$ & $\begin{array}{l}183.65 \\
(45.16)\end{array}$ & $\begin{array}{c}214 \\
(51.17)\end{array}$ & $\begin{array}{l}204.88 \\
(44.19)\end{array}$ \\
\hline
\end{tabular}

Each cell contains mean and (standard error) of the group total. * indicates that the mean is significantly different from 150 at the $10 \%$ level. 
Table 7: Predicted and Actual Decisions by Treatment, Period 1 and Period 25.

\begin{tabular}{|c|c|c|c|c|c|c|}
\hline & \multicolumn{2}{|c|}{ No Information } & \multicolumn{2}{|c|}{ Partial Information } & \multicolumn{2}{|c|}{ Full Information } \\
\hline & Actual & Predicted & Actual & Predicted & Actual & Predicted \\
\hline \multicolumn{7}{|c|}{ Large Capacity Subjects } \\
\hline \multirow{3}{*}{ Period 1} & 26.22 & 26.28 & 45.44 & 44.88 & 20.44 & 19.14 \\
\hline & $(9.43)$ & $(8.81)$ & $(11.58)$ & $(9.92)$ & $(3.99)$ & $(3.74)$ \\
\hline & 9 & 9 & 9 & 9 & 9 & 9 \\
\hline \multirow{3}{*}{ Period 25} & 42.60 & 32.44 & 44.38 & 47.51 & 51.89 & 46.74 \\
\hline & $(9.65)$ & $(5.84)$ & $(15.79)$ & $(15.41)$ & $(10.22)$ & $(7.04)$ \\
\hline & 5 & 5 & 8 & 8 & 9 & 9 \\
\hline \multicolumn{7}{|c|}{ Medium Capacity Subjects } \\
\hline \multirow{3}{*}{ Period 1} & 18.00 & 16.34 & 25.00 & 24.47 & 26.72 & 26.15 \\
\hline & $(4.02)$ & $(3.58)$ & $(5.27)$ & $(5.33)$ & $(4.88)$ & $(5.15)$ \\
\hline & 18 & 18 & 18 & 18 & 18 & 18 \\
\hline \multirow{3}{*}{ Period 25} & 27.67 & 31.41 & 25.00 & 26.90 & 32.89 & 27.64 \\
\hline & $(6.81)$ & $(5.40)$ & $(6.75)$ & $(5.30)$ & $(4.82)$ & $(2.63)$ \\
\hline & 18 & 18 & 18 & 18 & 18 & 18 \\
\hline \multicolumn{7}{|c|}{ Small Capacity Subjects } \\
\hline \multirow{3}{*}{ Period 1} & 23.56 & 23.59 & 19.56 & 16.08 & 24.89 & 23.63 \\
\hline & $(6.88)$ & $(6.87)$ & $(5.96)$ & $(6.80)$ & $(8.69)$ & $(8.48)$ \\
\hline & 9 & 9 & 9 & 9 & 9 & 9 \\
\hline \multirow{3}{*}{ Period 25} & 37.56 & 33.75 & 17.00 & 18.69 & 19.56 & 21.56 \\
\hline & $(8.94)$ & $(7.08)$ & $(6.83)$ & $(4.05)$ & $(9.06)$ & $(8.82)$ \\
\hline & 9 & 9 & 9 & 9 & 9 & 9 \\
\hline
\end{tabular}

Each cell contains mean, standard error and number of observations. 


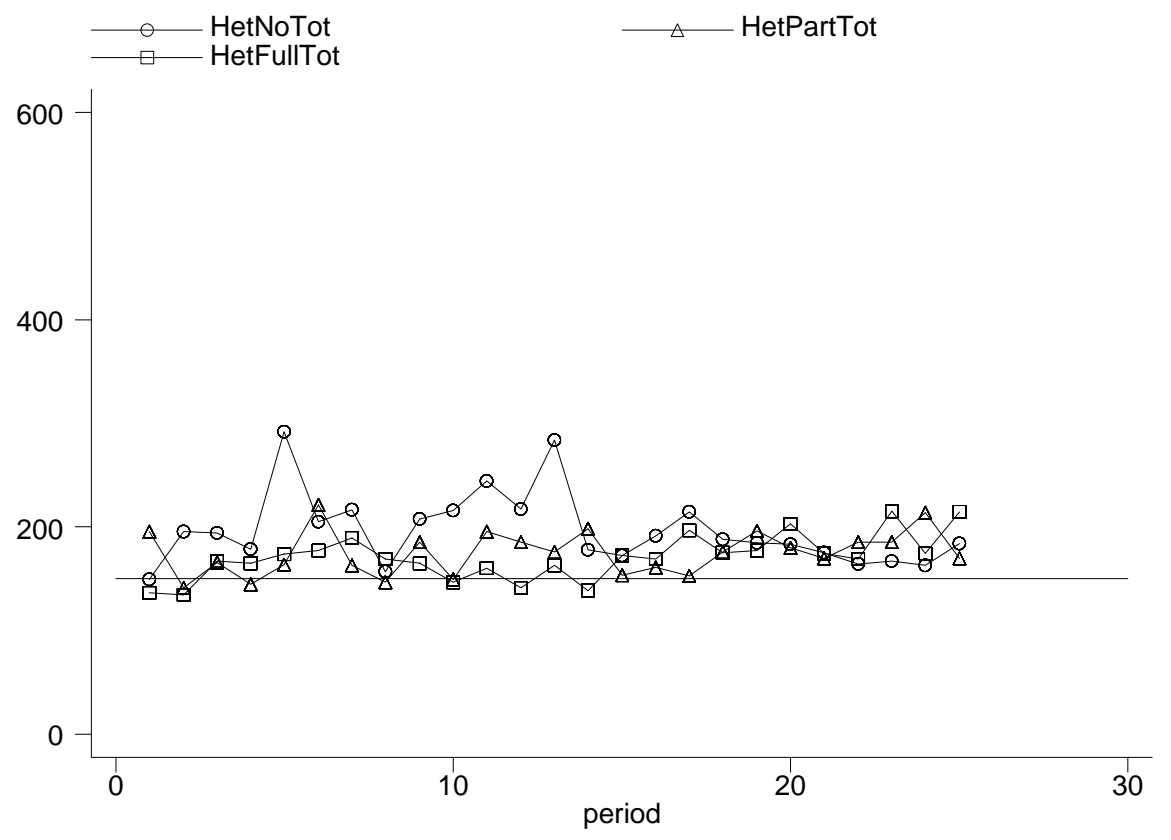

Figure 1: Average Group Totals by Treatment and Period, Heterogeneous Agents.

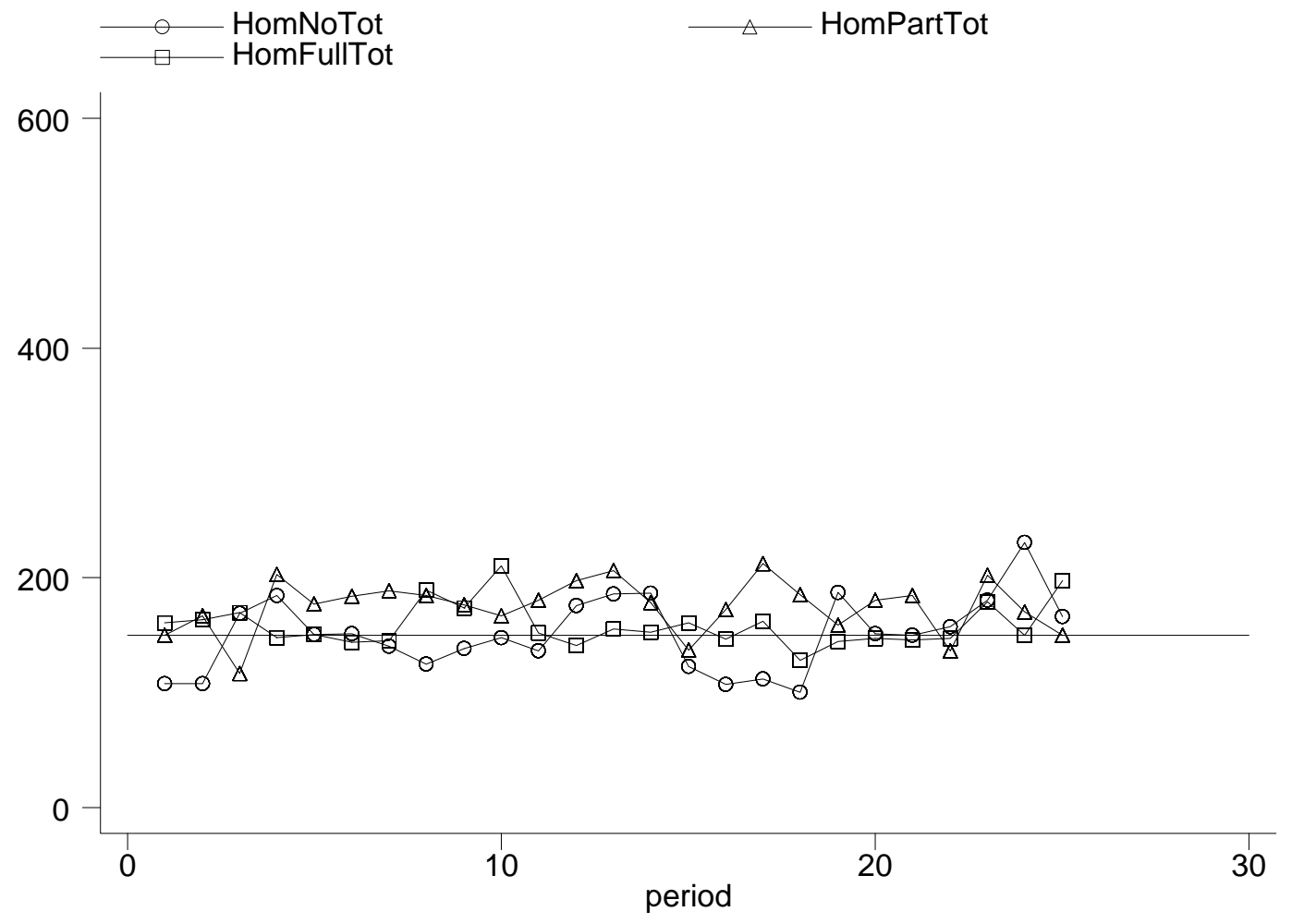

Figure 2: Average Group Totals by Treatment and Period, Homogeneous Agents. 

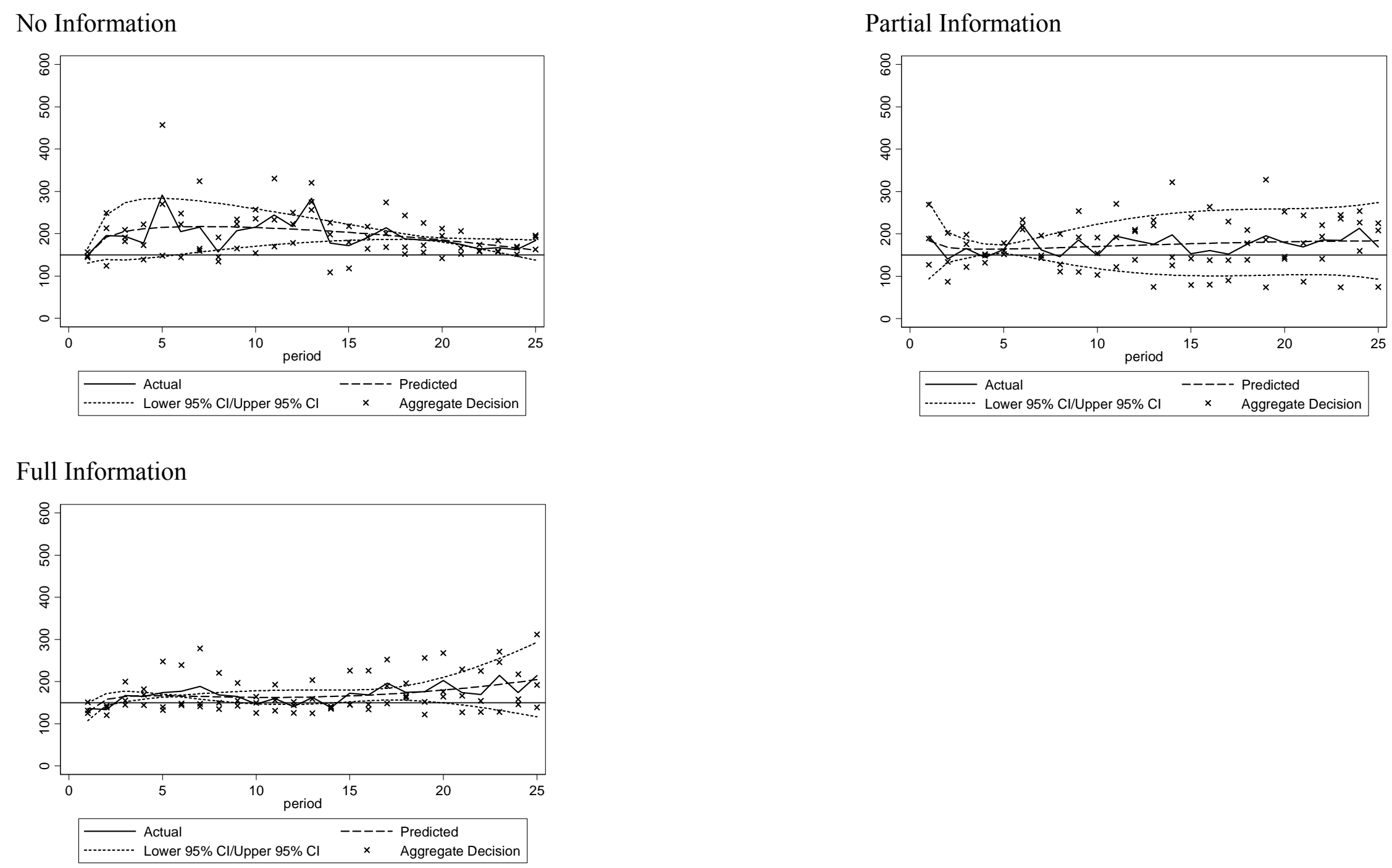

Figure 3: Average Group Totals with Predictions and Confidence Intervals from Regression, by Treatment, Heterogeneous Agents. 

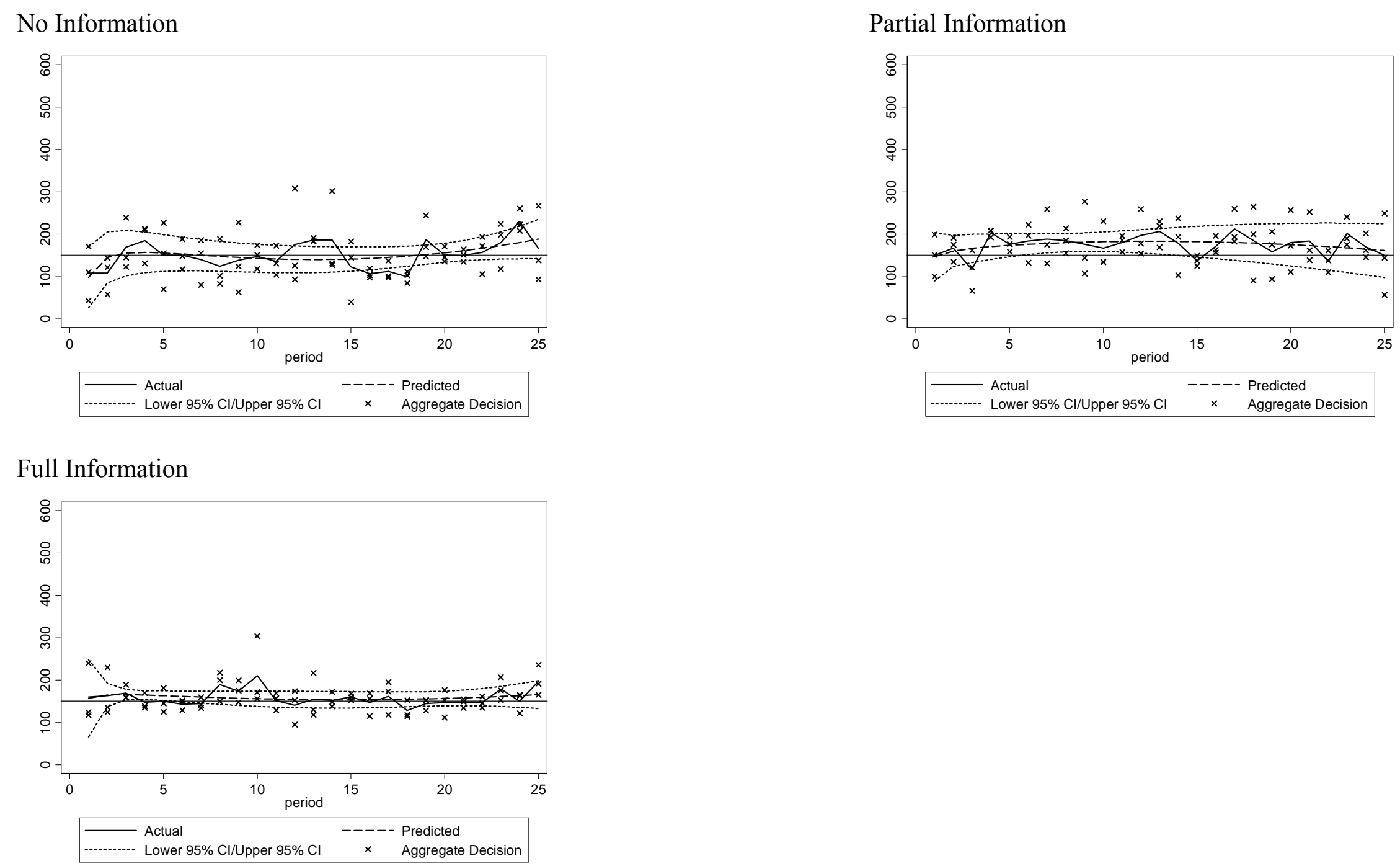

Figure 4: Average Group Totals with Predictions and Confidence Intervals from Regression, by Treatment, Homogeneous Agents. 


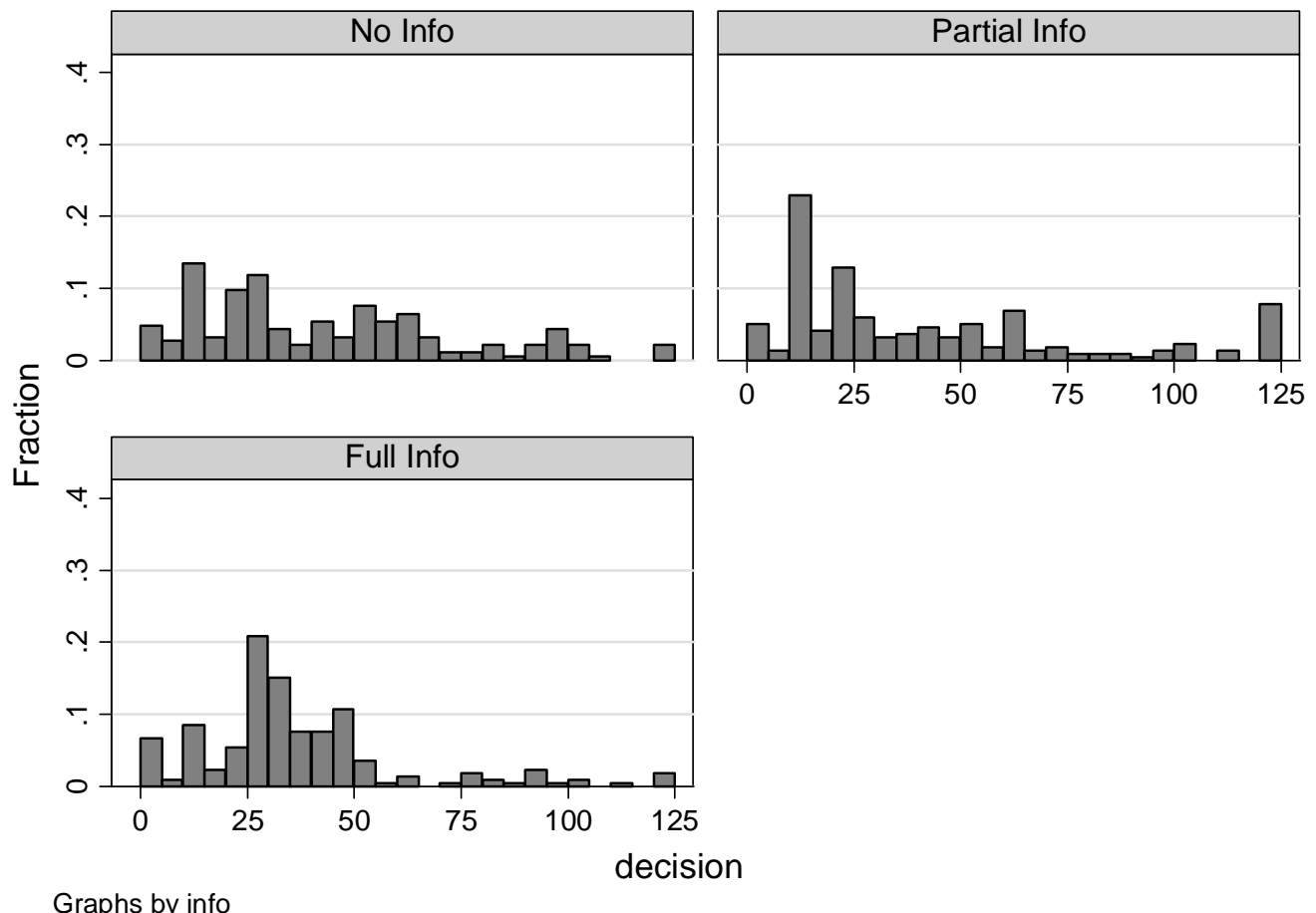

Figure 5: Distributions of Individual Decisions for Large Capacity Subjects, by Information.
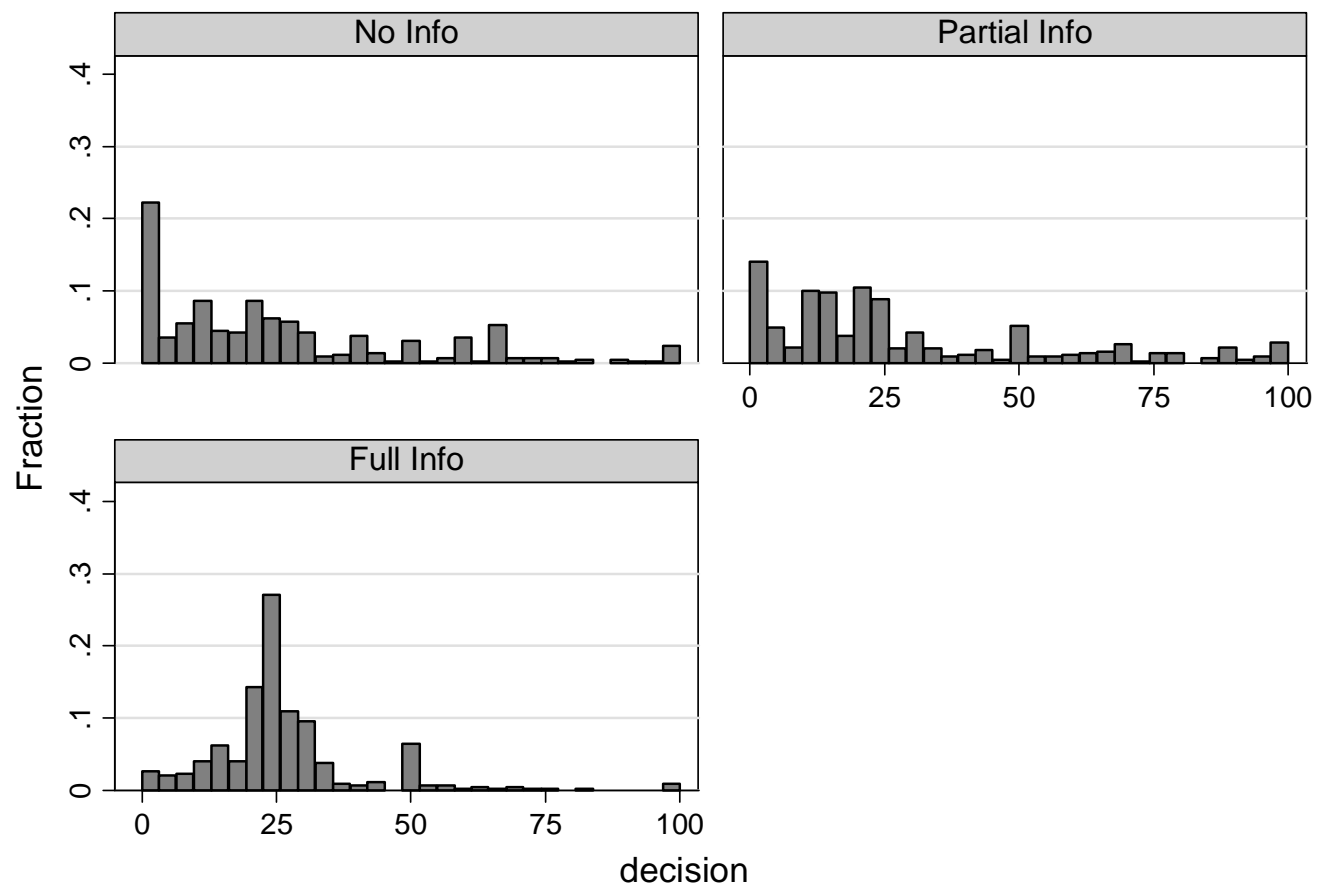

Graphs by info

Figure 6: Distributions of Individual Decisions for Medium Capacity Subjects, by Information. 


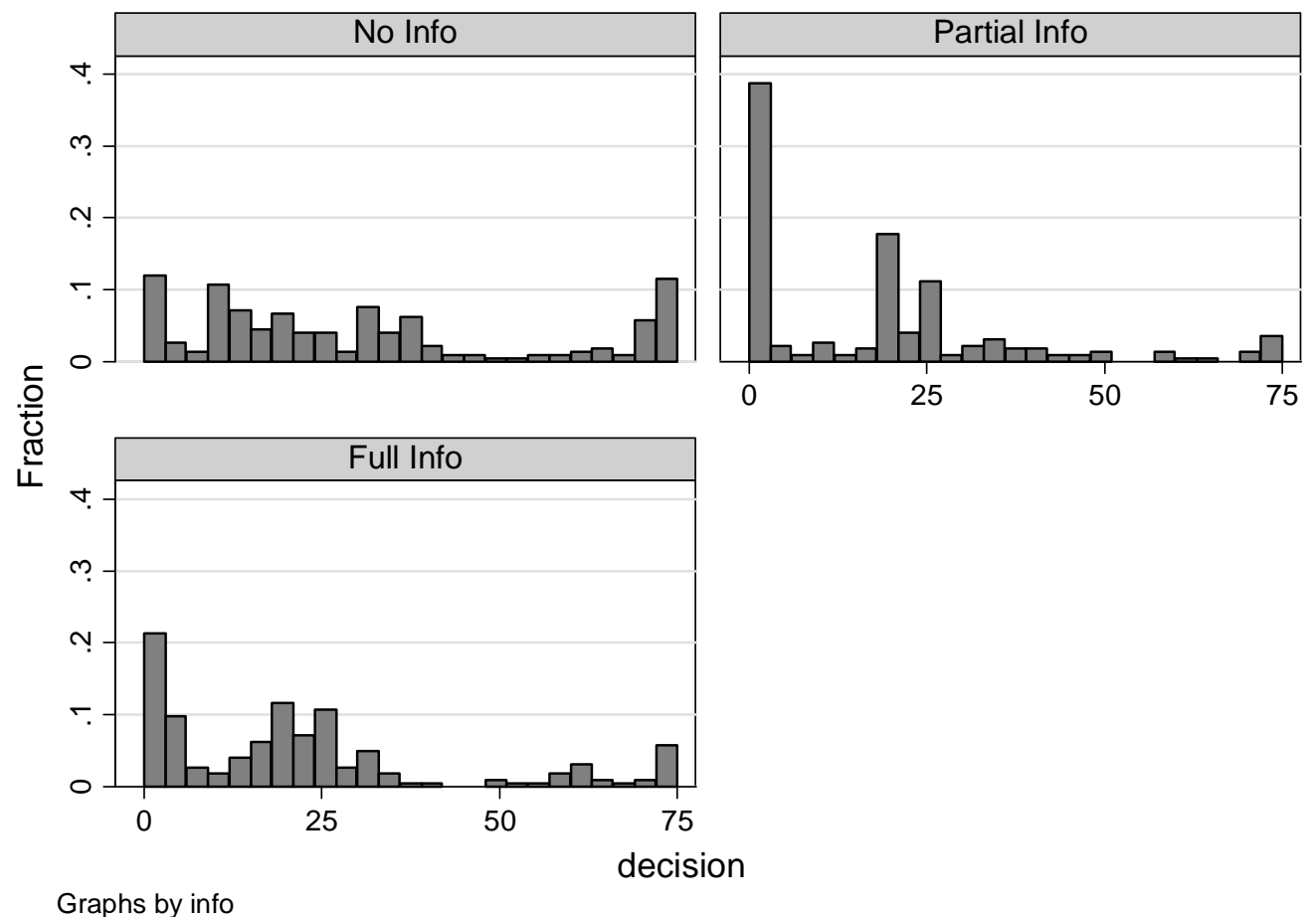

Figure 7: Distributions of Individual Decisions for Small Capacity Subjects, by Information. 

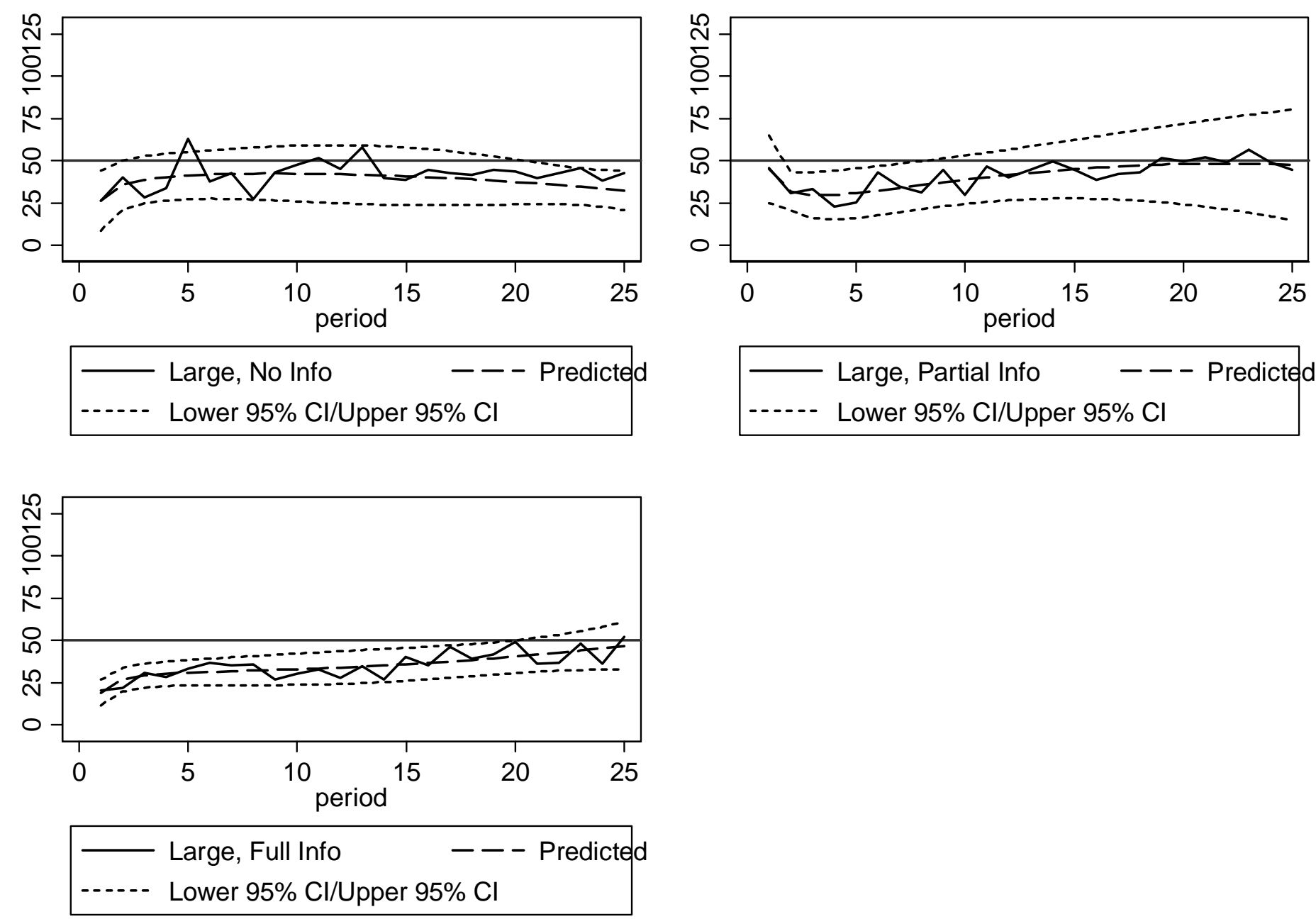

Figure 8: Average Decisions, Predictions and Confidence intervals from regression, Large Capacity Subjects. 

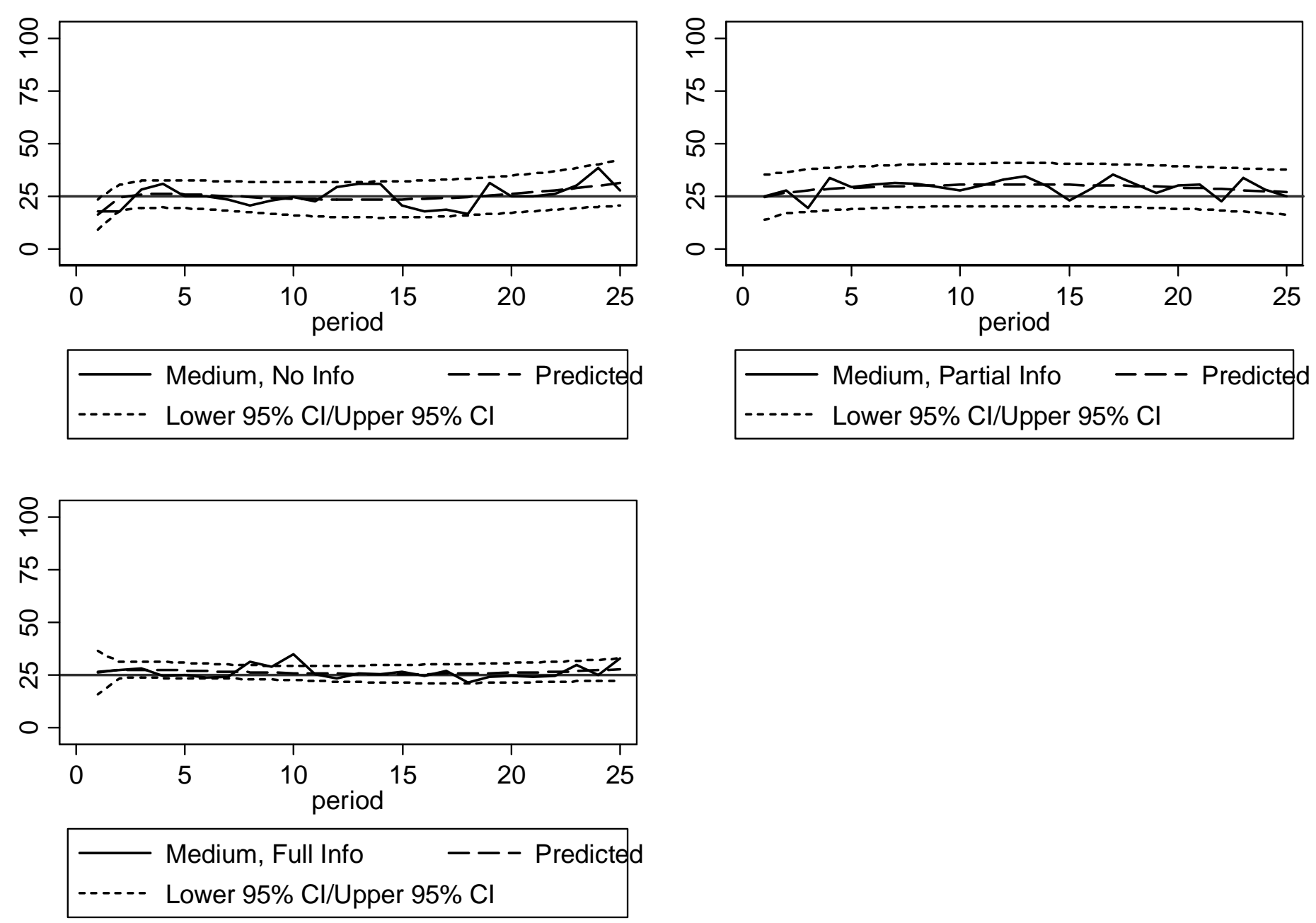

Figure 9: Average Decisions, Predictions and Confidence intervals from regression, Medium Capacity Subjects. 


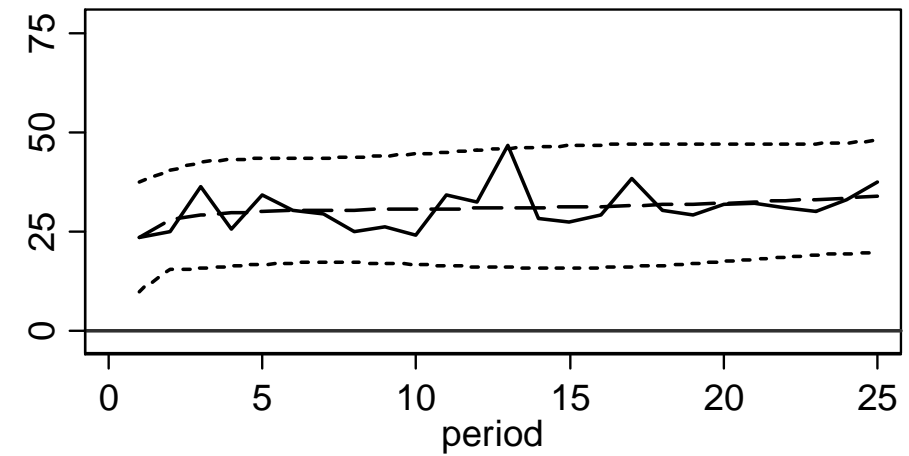

Small, No Info Lower 95\% Cl/Upper 95\% Cl
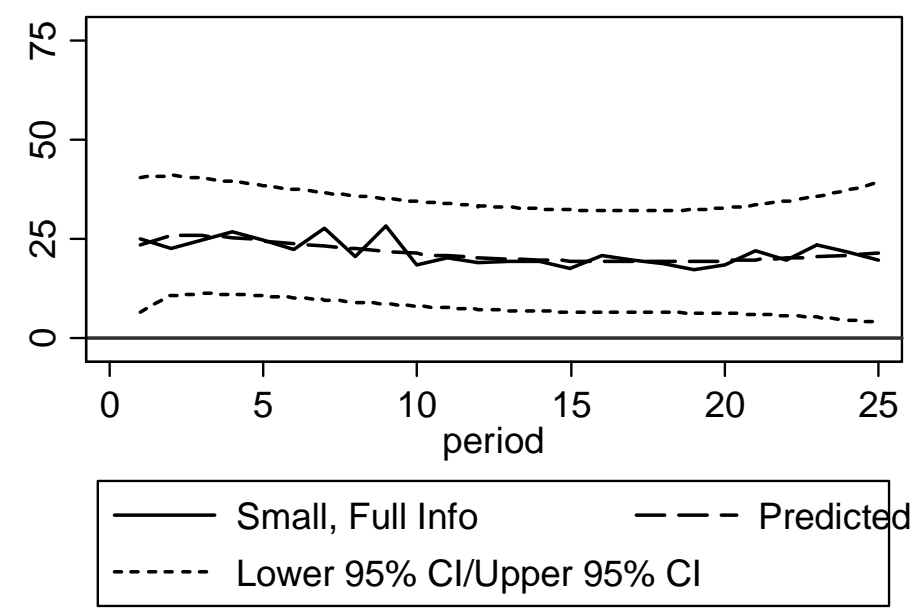

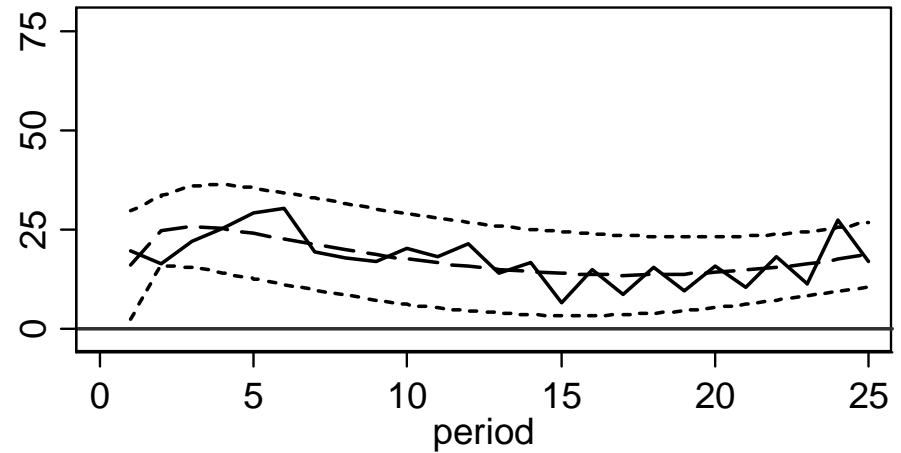

- Small, Partial Info - - - Predicted -..-.- Lower 95\% Cl/Upper 95\% Cl

Figure 10: Average Decisions, Predictions and Confidence intervals from regression, Small Capacity Subjects. 


\section{$\underline{\text { Appendix B- Instructions }}$}

This appendix is a compilation of the instructions are presented to the subjects. Comments, in italics, have been inserted to point out the differences between the treatments. The first part was common to all sessions

\section{Instructions}

This is a session in an experiment in the economics of decision making. During this session your payoffs will be reported in lab dollars. It is possible that you could lose money in this session. As a result everyone will be given an opening balance of 250 lab dollars. If at anytime your cumulative payoff (which includes this opening balance) falls below 0 lab dollars you will be excused from this part of the session. Despite this if you follow the instructions carefully you may earn a considerable amount of money. This research is being funded by the Senate Research Committee at Lakehead University.

\section{$\underline{\text { Overview }}$}

Today's session will be conducted using the computer network located in our laboratory. The session will consist of 2 parts which will each last 25 periods. We will begin after everyone has finished reading the instructions and completed 5 practice periods. Please refrain from talking during the session. Each period will proceed as follows.

\begin{tabular}{|l|l|}
\hline What the Computer does & What you do \\
\hline Start period. & \\
\hline & $\begin{array}{l}\text { Choose a "decision number" } \\
\text { and enter it in the appropriate } \\
\text { box on your computer screen. }\end{array}$ \\
\hline $\begin{array}{l}\text { Collect decision numbers, Calculates } \\
\text { individual payoffs, and returns results }\end{array}$ & $\begin{array}{l}\text { Check your payoff and } \\
\text { cumulative payoff }\end{array}$ \\
\hline & \\
\hline Start next period or end section & \\
\hline
\end{tabular}

Now here are the details. 
Full information, homogeneous payoff functions.

You have been assigned to a group of six (yourself and five other) participants. This will be your group for the entire session. Everyone in your group has the same instructions. This part will consist of 25 periods. In each period you (and the others in your group) will be asked to choose a number between 0 and 100 and to enter it into the computer. This is your Decision Number.

Full information, heterogeneous payoff functions and Partial Information.

You have been assigned to a group of six (yourself and five other) participants. This will be your group for the entire session. This part will consist of 25 periods. In each period you (and the others in your group) will be asked to choose a number and to enter it into the computer. This is your Decision Number.

No information.

You have been assigned to a group of participants. This will be your group for the entire session. This part will consist of 25 periods. In each period you (and the others in your group) will be asked to choose a number and to enter it into the computer. This is your Decision Number.

\section{All Treatments}

Your Total Payoff for each period is the sum of your Private Payoff and your Group Payoff:

$$
\text { Total Payoff }=\text { Private Payoff }+ \text { Group Payoff }
$$

Full information, homogeneous payoff function.

Your Private Payoff depends only on your own Decision Number. Table 1 in your folder shows the Private Payoff for each possible Decision Number. For example if your Decision Number were 60 Table 1 shows that your Private Payoff would be 21.80 lab dollars. Or if you had chosen 30 your Private Payoff would be 15.20 lab dollars. Notice that the higher your Decision Number the higher your Private Payoff.

Full information, heterogeneous payoff function. 
Your Private Payoff depends only on your own Decision Number. You have been randomly assigned to a player type. Half (3) of the people in your group must choose their Decision Number between 0 and 125. The other half of the people in your group must choose their Decision Number between 0 and 75. The payoffs are also different for both types of people so that the Private payoff to choosing 10 for people whose decision numbers can range between 0 and 125 is different than the payoff to choosing 10 for people whose decision number can range between 0 and 75 .

Table 1 in your folder shows the Private Payoff for each of your possible Decision Numbers. For example if you were to choose 30 Table 1 shows your Private Payoff for choosing that Decision Number.

If your Decision Numbers must be less than 125 Table 1 shows you that your Private Payoff for choosing 30 would be 6.95 lab dollars.

If your Decision Numbers must be less than 75 Table 1 shows you that your Private Payoff for choosing 30 would be 20.95 lab dollars.

Notice that the higher your Decision Number the higher your Private Payoff.

Table 2 in your folder shows the Private Payoffs for each of the possible Decision Numbers for someone of the other type. For example Table 2 shows the Private Payoff to a participant of the other type who chose 30 .

If the participant of the other type's Decision Numbers are always less than 75 then Table 2 shows that their Private Payoff for choosing 30 is 20.95 lab dollars.

Or, if the participant of the other type's Decision Numbers are always less than 125 Table 2 shows their Private Payoff for choosing 30 is 6.95 lab dollars.

Notice that the higher their Decision Number the higher their Private Payoff.

\section{Partial Information}

Your Private Payoff depends only on your own Decision Number. Table 1 in your folder shows the Private Payoff for each of your possible Decision Numbers. For example if you were to choose 30 Table 1 shows that your Private Payoff for choosing that Decision Number is 6.95 lab dollars.

Notice that the higher your Decision Number the higher your Private Payoff.

You do not know the Private Payoff of the other people in your group.

\section{All Treatments.}


The Group Payoff depends only on the Group Total and is the same for everyone in the group. If the Group Total is less than or equal to 150 then the Group Payoff will be a positive value equal to $30 \%$ of the difference between 150 and the Group Total. If the Group Total is greater than 150, the Group Payoff is a negative value equal to $30 \%$ of the difference between 150 and the Group Total. The Group Payoff can be written as the following function of the Group Total:

$$
\text { Group Payoff }= \begin{cases}0.3 *(150-\text { Group Total }) & \text { if Group Total }>150 \\ 0.3 *(150-\text { Group Total }) & \text { if Group Total } \leq 150\end{cases}
$$

For example if the Group Total were 170 then the Group Payoff for every member of the group would be $0.3 *(150-170)=-6.00$ lab dollars. Similarly if the Group Total were 140 then the Group Payoff for every member of the group would be $0.3 *(150-140)=3.00$ lab dollars. Notice that the higher the Group Total the lower the Group Payoff.

\section{Full information, homogeneous payoff functions.}

As a simple example, suppose that you chose 30 , and everyone else in your group chose 20. The Group Total would be 130 (the sum of your decision number and the decision numbers of everyone else in your group), your Private Payoff would be 15.20, the Group Payoff would be 6.00, and your Total Payoff would be 21.20 lab dollars.

Now suppose, that you had chosen 70 in the above example. The Group Total would be 170, your Private Payoff 23.20, the Group Payoff would be -6.00 , and your Total Payoff would be 17.20 lab dollars. Notice that the higher your Decision Number the higher your Private Payoff. But, the higher your Decision Number the higher the Group Total and the lower the Group Payoff.

\section{Full information, heterogeneous payoff functions.}

As a simple example, suppose that you chose 30 , and everyone else in your group chose 20. The Group Total would be 130 (the sum of your decision number and the decision numbers of everyone else in your group), your Private Payoff would be 6.95 if your decision numbers must be less than 125 and 20.95 if your decision numbers must be less than 75, the Group Payoff would be 6.00, and your Total Payoff would be 12.95 if your decision numbers are always less than 125, and 26.95 lab dollars if your decision numbers are always less than 75 .

Now suppose, that you had chosen 70 in the above example. The Group Total would be 170, your Private Payoff 18.95 if your decision numbers are always below 125 and 24.95 if your decision numbers are always below 75, the Group Payoff would be 6.00 , and your Total Payoff would be 12.95 or 18.95 lab dollars depending on what type you are. Notice that the higher your Decision Number the higher your Private Payoff. But, the higher your Decision Number the higher the Group Total and the lower the Group Payoff. 


\section{Partial Information.}

As a simple example, suppose that you chose 30, and everyone else in your group chose 20. The Group Total would be 130 (the sum of your decision number and the decision numbers of everyone else in your group), your Private Payoff would be 6.95, the Group Payoff would be 6.00, and your Total Payoff would be 12.95 lab dollars.

Now suppose, that you had chosen 70 in the above example. The Group Total would be 170, your Private Payoff 18.94, the Group Payoff would be -6.00, and your Total Payoff would be 12.95 lab dollars. Notice that the higher your Decision Number the higher your Private Payoff. But, the higher your Decision Number the higher the Group Total and the lower the Group Payoff.

\section{No Information.}

As a simple example, suppose that you chose 30, and that the sum of the decision numbers of everyone else in your group was 100. The Group Total would be 130 (the sum of your decision number and the decision numbers of everyone else in your group), your Private Payoff would be 20.95, the Group Payoff would be 6.00, and your Total Payoff would be 26.95 lab dollars.

Now suppose, that you had chosen 70 in the above example. The Group Total would be 170, your Private Payoff 24.95, the Group Payoff would be -6.00, and your Total Payoff would be 18.95 lab dollars. Notice that the higher your Decision Number the higher your Private Payoff. But, the higher your Decision Number the higher the Group Total and the lower the Group Payoff.

\section{Full and partial information.}

Your payment for this session will be the sum of your earnings in each of the 25 periods. Your earnings will be converted from lab dollars to Canadian at the rate of 1 lab dollar is equal to $21 / 2$ cents Canadian. In the event that you do lose your opening balance you will be informed by the computer that you are Bankrupt and will not be able to participate in the rest of this part of the experiment. At this point the rest of the people in your group will be informed that there is now one less person whose decision number is being added into the group total.

\section{No information.}

Your payment for this session will be the sum of your earnings in each of the 25 periods. Your earnings will be converted from lab dollars to Canadian at the rate of 1 lab dollar is equal to $21 / 2$ cents Canadian. In the event that you do lose your opening balance you will be informed by the computer that you are Bankrupt and will not be able to participate in the rest of this part of the experiment.

\section{All treatments.}


Please answer the following question:

Use TABLE 1 to fill in the portion of the record sheet below assuming that you chose 65 , the Group Total was 400 and the group payoff is $30 \%$ of the difference between 150 and the Group Total if the Group Total is above 150 and 30\% of the difference between 150 and the Group Total if the Group Total is less than or equal to 150

\begin{tabular}{|c|c|c|c|c|c|c|}
\hline Period & $\begin{array}{c}\text { Decision } \\
\text { Number }\end{array}$ & $\begin{array}{c}\text { Private } \\
\text { Payoff }\end{array}$ & $\begin{array}{c}\text { Group } \\
\text { Total }\end{array}$ & $\begin{array}{c}\text { Group } \\
\text { Payoff }\end{array}$ & $\begin{array}{c}\text { Total } \\
\text { Payoff }\end{array}$ & $\begin{array}{c}\text { Cumulative } \\
\text { Payoff }\end{array}$ \\
\hline Practice & & & & & & \\
\hline
\end{tabular}

Please raise your hand when you are done so that the monitor can check your answer.

Before we begin we will conduct five practice periods. These practice periods are intended to help you understand today's experiment. Any earnings you make during the practice periods will not be included in your payment at the end of the session. The practice periods will differ from the actual periods in that the Group Total will be your decision number plus a random number chosen by the computer. The Group Total in the practice periods will be your decision number plus a random number between 0 and 500 . This random number is chosen by the computer so that each number between and including 0 and 500 has an equal chance of being selected.

Once the first practice period starts you will notice that the game window on the computer screen has four sections. The first section describes the Group Payoff function. This function is the same as described in the instructions above. The second section is labelled Scratch Pad. Using the Scratch Pad, you will be able to determine your payoff from different combinations of values for your Decision Number and the Group Total. Notice that you can change the Decision Number and the Group Total by typing numbers into the edit boxes or by using the arrow buttons located beside the edit boxes. Also notice that changing the Decision Number changes the Group Total. This is because the Group Total is the sum of your Decision Number, the Decision Numbers of those in your group and the random number and as a result when your Decision Number increases so does the Group Total. The third section of the screen is where you type your Decision Number. Once you have chosen your Decision Number and typed it into the edit box click on the Ok button to complete this part of the period. The fourth section of the screen contains two tabs which allow you to switch between the main screen and the history screen. If you click on the tab labelled history you will be able to see the outcome of all of the previous period in which you have participated. Please feel free to raise your hand and ask any questions you may have.

To help you understand the Scratch Pad please pick any valid decision number and type it into the box beside Your Decision Number on the scratch pad. Now pick a bigger number and type it into the box beside Group Total. Notice that the Group Total will always be bigger than your Decision Number as it is the sum of the Decision 
Numbers of everyone in your group. Now use the arrow buttons beside the box where you typed Your Decision Number to increase or decrease Your Decision Number. Notice the effect of these changes on your Total Payoff.

Once the practice periods have been completed we will begin the 25 periods for which you will be paid at the end of today's session. 